\section{CONCLUSIÓN}

La tasa de autopsias fue 59,5\%. Los resultados de la correlación anatomoclínica, su influencia en el asesoramiento a la familia para futuros embarazos y su contribución al conocimiento médico corroboran la importancia de la sistemática realización de autopsias en neonatología.

\section{REFERENCIAS}

1. Brodlie M, Laing IA, Keeling JW, et al. Ten years of neonatal autopsies in tertiary referral centre: retrospective study. BMJ 2002;324(7340):761-3.

2. Khong TY. Falling neonatal autopsy rates. BMJ 2002;324(7340):749-50.

3. Cohen M, Drut R. La autopsia en pediatría. Diagnóstico de situación en un hospital de pediatría de referencia. Arch Argent Pediatr 2003;101(3):166-70.

4. Farías S. La autopsia: presente...¿y futuro? Análisis estadístico de las autopsias realizadas en el Hospital de Niños "Ricardo Gutiérrez", entre enero 1980 y diciembre 2009. Rev Hosp Niños BAires 2012;54(244):4-14.

5. Goldman L, Sayson R, Robbins S, et al. The value of the autopsy in three medical eras. $N$ Engl J Med 1983;308(17):1000-5.

6. Kumar P, Angst DB, Taxy J, et al. Neonatal autopsies: a 10year experience. Arch Pediatr Adolesc Med 2000;154(1):38-42.

7. Swinton $\mathrm{CH}$, WeinerJ,Okah FA. The neonatal autopsy: can it be rvived? Am J Perinatol 2013;30(9):739-44.

8. Hickey L, Murphy A, Devaney D, etal. The value of neonatal autopsy. Neonatology 2012;101(1):68-73.

9. Rose C, Evans M, Tooley J. Falling rates of perinatal postmortem examination: are we to blame?. Arch Dis Child Fetal Neonatal Ed 2006;91(6):F465.

10. Burton JL, Underwood J. Clinical, educational, and epidemiologicalvalueofautopsy.Lancet2007;369(9571):147180.

11. Dhar V, Perlman M, Vilela MI, et al. Autopsy in a neonatal intensive care unit: utilization patterns and associations of clinicopathologic discordances. J Pediatr 1998;132(1):75-9.

12. Faye-Petersen OM, Guinn DA, Wenstrom KD. Value of perinatal autopsy. Obstet Gynecol 1999;94(6):915-20.

13. Custer JW, Winters BD, Goode V, et al. Diagnostic errors in the Pediatrics and Neonatal ICU: A Systematic Review. Pediatr Crit Care Med 2015;16(1):29-36.

14. Schnitzler E. Volver a la autopsia o seguir ignorando la verdad. Arch Argent Pediatr 2003;101(3):163-4.

15. EscardóF. Sentidoético dela autopsia. Boletín delaIICátedra de Pediatría 1964;2.

\title{
Concentración sérica de prolactina en la dermatitis atópica y su relación con la gravedad de la enfermedad
}

\author{
Serum prolactin levels in atopic dermatitis and the relationship with \\ disease severity
}

Dra. Burcu Tuğrul Ayanoğlua, Dra. Özgül Muştu Koryürek ${ }^{a}$ y Dra. Songül Yıldırım Başkara ${ }^{b}$

\section{RESUMEN}

Antecedentes. La prolactina actúa como modulador neuroendocrino de la proliferación de las células epiteliales de la piel y del sistema inmunitario cutáneo.

Objetivo. Evaluar la concentración sérica de prolactina en los pacientes con dermatitis atópica y su relación con gravedad de la enfermedad.

a. Aksaray Üniversitesi, Hospital de Formación e Investigación de Aksaray, Departamento de Dermatologíay Venereología. Aksaray, Turquía.

b. Aksaray Üniversitesi,Hospital deFormacióne Investigación de Aksaray, Departamento de Pediatría. Aksaray, Turquía.

Correspondencia:

Dra. Burcu Tuğrul Ayanoğlu: burcutugrul@yahoo.com

Financiamiento: Ninguno.

Conflicto de intereses: Ninguno que declarar.

Recibido: 20-12-2016

Aceptado: 16-5-2017

Publicado Primero en Internet: 28-8-2017
Métodos. El estudio se llevó a cabo en 46 pacientes con dermatitis atópicay 100 controles sanos deentre 0,5 y 19,5 años. El diagnóstico de dermatitis atópica se basó en las manifestaciones clínicas y se documentó la gravedad de la enfermedad. Se tomaron muestras de sangre venosa para medir la concentración de prolactina. Resultados. La concentración de prolactina no difirió entre los pacientes con dermatitis atópica y los controles, y no se estableció una relación entre la gravedad de la dermatitis atópica y la concentración sérica de prolactina. La prolactina no participa en la patogenia de la dermatitis atópica. Se necesitan otros estudios con tamaños muestrales más grandes y la medición de la concentración de prolactina en la piel para comprender la función de la prolactina en la patogenia de la dermatitis atópica. Palabras clave: dermatitis atópica, prolactina, índice SCORAD, niño.

http:/ / dx.doi.org/10.5546/ aap.2017.493

Texto completo en inglés:

http:/ / dx.doi.org/10.5546/aap.2017.eng.493

Cómo citar: Tuğrul Ayanoğlu B, Muştu Koryürek O, Yıldırım Başkara S. Concentración sérica de prolactina en la dermatitis atópica y su relación con la gravedad de la enfermedad. Arch Argent Pediatr 2017;115(5): 493-496. 


\section{INTRODUCCIÓN}

La dermatitis atópica (DA) es una dermopatía inflamatoria crónicamente recidivante asociada con interacciones complejas entre genes sensibles, el entorno del huésped, los defectos de la barrera cutánea y las respuestas sistémicas e inmunitarias locales. Esta enfermedad se caracteriza por lesiones eccematosas y prurito intenso que suele aparecer durante la primera infancia pero que también puede comenzar o continuar durante la adultez. Se han desarrollado sistemas de puntuación para su uso en ensayos clínicos. ${ }^{2}$

La prolactina (PRL) es un neuropéptido conformado por péptidos múltiples producida por lactotropos en el lóbulo anterior de la hipófisis, conocida por sus efectos lactogénicos y mamotrópicos. Se ha planteado como hipótesis que la formación de un "circuito de prolactina" entre el sistema nervioso central y la piel permite que la prolactina actúe como modulador neuroendocrino de las células epiteliales de la piel y del sistema inmunitario cutáneo. ${ }^{3} \mathrm{La}$ prolactina tiene una función importante en las reacciones inmunitarias y ejerce un efecto proliferativo sobre los queratinocitos mediante la unión de sitios específicos. En estudios previos, se evaluó la asociación entre la concentración de prolactina y la psoriasis como una dermopatía hiperproliferativa de etiología multifactorial; $\sin _{5-7}$ embargo, los resultados parecen contradictorios. ${ }^{5-7}$ Hasta el momento, no se cuenta con conocimientos cabales sobre la hiperproliferación epidérmica presente en la psoriasis y la dermatitis atópica y sus mecanismos subyacentes. ${ }^{8}$

Solo se dispone de información aislada acerca de la concentración de prolactina en los niños con dermatitis atópica. En este estudio, se midió la concentración sérica de prolactina en los pacientes con dermatitis atópica y se analizó la correlación entre la actividad de la enfermedad y la prolactina.

\section{MATERIALES Y MÉTODOS}

\section{Selección de pacientes:}

Estudio de casos y controles prospectivo y analítico llevado a cabo en el Hospital de Formación e Investigación de Aksaray entre marzo de 2014 y enero de 2015. El comité de ética local aprobó el protocolo del estudio. Se obtuvo el consentimiento informado por escrito de cada paciente y sus padres. Se estudió a 46 pacientes con dermatitis atópica exacerbada y a 100 pacientes que coincidieran en sexo y edad ingresados a los consultorios externos de pediatría y dermatología por afecciones diferentes a la dermatitis atópica en el mismo período. Se seleccionó al grupo del estudio entre los pacientes que ya se hubieran realizado análisis de sangre como parte de la rutina. Los siguientes fueron los criterios de exclusión: negativa a participar en el estudio, afecciones médicas o uso de fármacos que podrían alterar la concentración de prolactina, p. ej., trastornos tiroideos, insuficiencia renal o hepática, embarazo, trastornos autoinmunitarios o inflamatorios que podrían ser concurrentes con la dermatitis atópica. El diagnóstico de dermatitis atópica se basó en las manifestaciones clínicas y los antecedentes de la enfermedad. Todos los pacientes y sus padres completaron un cuestionario, que incluía sus datos demográficos y antecedentes médicos (edad, sexo, duración de la enfermedad, cantidad de recidivas). Se documentó la gravedad de la enfermedad según el índice SCORAD (SCORing Atopic Dermatitis), que es el sistema de puntuación de la dermatitis atópica con mejor valoración. Para medir el alcance de la dermatitis atópica con el índice SCORAD, se aplica la "regla de los nueves" a una imagen de las lesiones inflamatorias del paciente de frente y de espalda. El resultado sobre el alcance va de 0 a 100 . La gravedad según el índice SCORAD consta de seis elementos: eritema, pápulas/edema, excoriación, liquenización, exudación/ costras y xerosis. Cada elemento se puntúa de 0 a 3 . Los elementos subjetivos incluyen la valoración diaria de prurito e insomnio. La siguiente es la fórmula del índice SCORAD: A / $5+$ $7 \mathrm{~B} / 2+\mathrm{C}$. En esta fórmula, A representa el alcance (de 0 a 100), B es la gravedad (de 0 a 18) y C, los síntomas subjetivos (de 0 a 20). ${ }^{2}$ Un dermatólogo consultor estuvo a cargo de la información clínica, el diagnóstico y la evaluación según el índice SCORAD.

\section{Medición bioquímica}

Las muestras de sangre venosa se obtuvieron de cada participante (pacientes con dermatitis atópica exacerbada y los controles) entre las 8 y las 9 de la mañana, una sola vez. Se midió la concentración sérica de prolactina mediante quimioluminiscencia (Abbott, EE. UU.). A continuación se detallan los valores normales: de 5,30 a $63,3 \mathrm{ng} / \mathrm{ml}$ para los lactantes de 2 a 12 meses de edad; de 4,40 a 29,7 ng/ml para los niños de 2 a 
3 años; de 2,63 a $21 \mathrm{ng} / \mathrm{ml}$ para los niños de 4 a 11 años; de 2,84 a $24 \mathrm{ng} / \mathrm{ml}$ para los varones de 14 a 18 años y de 2,52 a $16,9 \mathrm{ng} / \mathrm{ml}$ para las mujeres de 14 a 18 años. En el caso de los mayores de 18 años, los valores normales fueron de 2,5 a $18 \mathrm{ng} / \mathrm{ml}$ para los hombres y de 1,2 a $30 \mathrm{ng} / \mathrm{ml}$ para las mujeres.

\section{Análisis estadístico}

Todos los datos se analizaron con el programa SPSS versión 20.0, con la prueba U de MannWhitney y la correlación de Spearman para la evaluación estadística. Un valor de $p<0,05$ se consideró significativo.

\section{RESULTADOS}

En este estudio se incluyó a 46 pacientes con dermatitis atópica (30 de sexo masculino y 16 de sexo femenino), de entre 0,5 y 19,5 años de edad (media: 5,95 $\pm 4,71$ años) y a 100 controles (60 de sexo masculino y 40 de sexo femenino), de entre 0,16 y 16 años de edad (media: 6,46 $\pm 4,27$ años).

La mediana de duración de la dermatitis atópica fue 1 año (intervalo: de 0,08 a 16,25 años) y la mediana de recidivas era de 2 por año (intervalo: de 1 a 24). La mediana del puntaje SCORAD fue de 31 (de 9 a 64).

Ninguno de los pacientes o los controles presentó hiperprolactinemia. La mediana (el intervalo) de la concentración sérica de prolactina fue de $10,54 \mathrm{ng} / \mathrm{ml}$ (de 3,92 a 30,24) en los pacientes con dermatitis atópica y de 11,47 (de 3,13 a 48,84 ) en los controles; $p: 0,267$. No se observaron diferencias significativas en la concentración de prolactina de ambos grupos $(p>0,05)$.

No se estableció una correlación significativa entre la concentración de prolactina y el sexo, la duración, la cantidad de recidivas y el puntaje de dermatitis atópica ( $p>0,05$, correlación de Spearman).

\section{DISCUSIÓN}

En este estudio, la concentración sérica de prolactina de los pacientes con dermatitis atópica no fue mayor que la de los individuos sin atopia. Además, no se estableció una correlación entre la gravedad de la enfermedad y la concentración sérica de prolactina. Se publicaron algunos informes sobre la concentración de prolactina en la dermatitis atópica. En un estudio similar al nuestro, Handjani y col. informaron que no observaron diferencias significativas entre la concentración de prolactina de los pacientes con psoriasis y dermatitis atópica y el grupo de referencia. ${ }^{9}$ En el estudio de Kasperska-Zajac y col., se midió la concentración sérica de prolactina de 13 pacientes de sexo femenino con síndrome de dermatitis / eccema atópico y se la comparó con la de 14 participantes sanos. El estudio no logró detectar diferencias significativas en la concentración sérica basal de prolactina de las pacientes y los participantes sanos, como en nuestro estudio. ${ }^{10}$ Giasuddin y col. determinaron la concentración sérica de prolactina de 12 pacientes con psoriasis vulgar y hallaron que era significativamente más alta que en los 9 pacientes con dermatitis atópica y los 20 controles, aunque no observaron diferencias significativas entre los pacientes con dermatitis atópica y los controles. ${ }^{7}$

Girolomoni y col. demostraron que la prolactina en una concentración fisiológica es capaz de estimular y mantener la proliferación de queratinocitos, lo que podría ser relevante en condiciones de hiperproliferación epidérmica, como la psoriasis y la dermatitis atópica. ${ }^{4}$

La hiperproliferación epidérmica constituye una observación clínica importante en la dermatitis atópica y, además de participar en la respuesta inmunitaria, los queratinocitos contribuyen a la patología de la dermatitis atópica debido a un cambio en sus características de desarrollo. ${ }^{8}$ Jensen y col. informaron que la proliferación de la epidermis es 5 veces mayor en las lesiones de los pacientes con dermatitis atópica en comparación con los individuos sanos. ${ }^{11}$

Se publicaron algunos informes sobre la concentración de prolactina en la psoriasis, donde la hiperproliferación de queratinocitos es el sello distintivo de la enfermedad, de manera similar a la dermatitis atópica. ${ }^{7}$ Según los informes de algunos estudios, la concentración de prolactina es más alta en los pacientes con psoriasis, ${ }^{6,7}$ mientras que otros estudios no establecieron ninguna diferencia significativa. ${ }^{5,12}$

Aún no se han dilucidado enteramente los mecanismos subyacentes de la hiperproliferación de queratinocitos observada en las dermopatías inflamatorias como la dermatitis atópica y la psoriasis, aunque se sabe que, especialmente, los factores de crecimiento y las citocinas, como el TNF- $\alpha$, el IFN- $\gamma$ y la IL-1, participan en el desarrollo de los queratinocitos. ${ }^{13}$

Conforme a los estudios, la prolactina es parte de la etiopatogenia de la psoriasis. ${ }^{12,14} \mathrm{Sin}$ embargo, tal vez la prolactina no cumpla ninguna 
función en la etiopatogenia de la dermatitis atópica. La hiperplasia epidérmica observada en la dermatitis atópica y la psoriasis podrían ser provocadas por mecanismos diferentes. Por ejemplo, se demostró que la IL-21 y la IL-23 inducen la hiperplasia epidérmica solo en la psoriasis. ${ }^{13}$ La histamina puede aumentar la proliferación de queratinocitos humanos en los pacientes con dermatitis atópica de manera diferente a los casos de psoriasis. ${ }^{8}$

En un estudio realizado por El-Khateeb y col., se observó que la concentración de prolactina era significativamente más alta en las lesiones cutáneas que en la piel con psoriasis y sin lesiones y que en el suero. Los autores informaron que el aumento significativo de la concentración de prolactina en las lesiones cutáneas en comparación con el suero en la psoriasis había direccionado la suposición de un aumento en la producción de prolactina a nivel local en las lesiones cutáneas de la psoriasis. ${ }^{15}$ La ausencia de diferencias en la concentración de prolactina observada en nuestro estudio y en estudios previos podría deberse a la producción local de prolactina en las lesiones atópicas de manera similar a lo que ocurre en la psoriasis.

Una de las limitaciones de nuestro estudio fue que se midió la concentración de prolactina solamente una vez y solo durante la exacerbación. Los pacientes con dermatitis atópica no suelen ingresar a los consultorios externos cuando están en remisión. Otra limitación del estudio fue el tamaño pequeño de la muestra en comparación con los individuos sin atopia. El pequeño tamaño muestral podría ser otro factor contribuyente a la falta de diferencias en la concentración de prolactina.

A modo de conclusión, nuestros resultados no respaldan el aumento de la secreción de prolactina en la dermatitis atópica ni la relación con los procesos inflamatorios inmunitarios asociados con la dermatitis atópica. No obstante, podrían realizarse estudios futuros con tamaños muestrales más grandes para medir la concentración de prolactina en la piel y determinar la asociación posible con la gravedad de la enfermedad.

\section{REFERENCIAS}

1. Leung DY, Boguniewicz M, Howell MD et al. New insights into atopic dermatitis. J Clin Invest 2004;113(5):651-7.

2. European Task Force on Atopic Dermatitis. Severity scoring of atopic dermatitis: the SCORAD index. Dermatology 1993;186(1):23-31.

3. Paus R. Does prolactin play a role in skin biology and pathology? Med Hypotheses 1991;36(1):33-42.

4. Girolomoni G, Philips JT, Bergstresser PR. Prolactin stimulates proliferation of cultured human keratinocytes. J Invest Dermatol 1993;101(3):275-9.

5. Gorpelioglu C, Gungor E, Alli N. Is prolactin involved in etiopathogenesis of psoriasis? J Eur Acad Dermatol Venereol 2008;22(9):1135-6.

6. Dilmé-Carreras E, Martín-Ezquerra G,Sánchez-Regaña M, et al. Serum prolactin levels in psoriasis and correlation with cutaneous disease activity. Clin Exp Dermatol 2011;36(1): 29-32.

7. Giasuddin AS, El-Sherif AI, El-Ojali SI. Prolactin: does it have a role in the pathogenesis of psoriasis? Dermatology 1992;197(2):119-22.

8. Glatzer F, Gschwandtner M, Ehling S, et al. Histamine induces proliferation in keratinocytes from atopic dermatitis patients. J Allergy Clin Immunol 2013;132(6): 1358-67.

9. Handjani F, Saki N, Ahrari I, et al. Serum prolactin levels in psoriasis vulgaris. ISRN Dermatology 2014;2014:586049.

10. Kasperska-Zajac A, Brzoza Z, Rogala B. Serum prolactin concentration in patients suffering from severe atopic eczema/dermatitis syndrome. Centr Eur J Immunol 2008;33(2):54-5.

11. Jensen JM, Fölster-Holst R, Baranowsky A, et al. Impaired sphingomyelinase activity and epidermal differentiation in atopic dermatitis. J Invest Dermatol 2004;122(6):1423-31.

12. Robati RM, ToossiP, Rahmati-RoodsariM, etal. Association of Psoriasis Severity with Serum Prolactin, Thyroid Hormones, and Cortisol before and after Treatment. Scientific World Journal 2013:921819.

13. Keen MA, Hassan I. Serum Prolactin Levels in Psoriasis and its Association with Disease Activity: A Case-Control Study. Indian J Dermatol 2014;59(6):562-6.

14. Roman II, Constantin AM, Marina ME, et al. The role of hormones in the pathogenesis of psoriasis vulgaris. Clujul Med 2016;89(1):11-8.

15. El-Khateeb EA, Zuel-Fakkar NM, Eid SM, et al. Prolactin level is significantly elevated in lesional skin of patients with psoriasis. Int J Dermatol 2011;50(6):693-6. 